\title{
ReGAE 5: Can we improve the surgical journey for African-Caribbean patients undergoing glaucoma filtration surgery? Some preliminary findings
}

\author{
Vinette Cross \\ Peter Shah \\ Martin Glynn \\ Shivani Chidrawar \\ Centre for Health and Social Care \\ Improvement, University \\ of Wolverhampton, Wolverhampton, \\ United Kingdom
}

\begin{abstract}
Aim: To explore the experiences of African-Caribbean patients who had undergone filtration surgery for advanced glaucoma.

Methods: Semi-structured qualitative interviews were used to collect the data and an interview guide was developed. Participants recounted when they first became aware of a problem with their eyes and their feelings at the time. Subsequently they were probed about their subjective experiences of becoming a glaucoma patient, receiving treatment, the decision to undergo surgery, and its aftermath. The perceptions of three participants from three different generations of African-Caribbean men were selected from the larger study for presentation in this paper. Interview transcripts were subjected to narrative analysis.

Results: The concept of patient-partnership was re-framed in terms of mentorship. Surgeon-patient relationships are central to developing effective coping strategies. Support to face the ordeals ahead, challenge to take on new responsibilities, and help to envision a meaningful life with glaucoma are fundamental to fostering trust and maintaining motivation to continue.

Conclusions: The use of patient narratives provides a valuable a resource for enhancing communication skills and patient-centered care in the hospital eye service.
\end{abstract}

Keywords: glaucoma, secondary eye-care, African-Caribbean, filtration surgery, trabeculectomy

\section{Introduction}

In medicine narrative accounts of their illness by health service users and participants in clinical trials are recognised increasingly as a rich resource for understanding, beyond that afforded by clinical examination, formal case history or quantitative research methods. ${ }^{1-4}$ In research, narratives "help to set a patient-centered agenda, may challenge received wisdom, and may generate new hypotheses". ${ }^{5}$ Often central to such narratives are doctor-patient relationships, and the extent to which patients' trust and confidence influences long-term outcomes of care. ${ }^{6}$ Impaired doctor-patient relationships are cited as limiting opportunities to improve outcomes from chronic disease, particularly for patients in Black and minority ethnic (BME) communities. ${ }^{7-9}$ Therefore, there is a continuing need for research into how health care processes and outcomes are influenced by doctor-patient communication and relationships, particularly in relation to improving outcomes from chronic disease among BME communities.

Recently it has been suggested that glaucoma specialists' knowledge of patients' subjective attitudes to glaucoma-related issues deserves further investigation. ${ }^{10}$ Glaucoma is a major cause of irreversible blindness in people of African descent, with research suggesting a higher prevalence in males. ${ }^{11}$ Lack of awareness of risk, 
low levels of referral, and under-utilization of the primary eye-care service have all been identified as issues associated with preventing unnecessary numbers of Black people becoming blind because of the disease. ${ }^{12-15}$ In refractory, progressive and potentially blinding glaucoma, such as that observed in the African-Caribbean eye, filtration surgery (trabeculectomy) is the surgical option of choice when topical ocular medications and/or laser therapy have failed to achieve adequate control of intraocular pressure (IOP). The aim is to produce long term functioning drainage blebs with optimal IOP and a good safety profile. This is particularly important in young patients, African-Caribbean patients, and patients with severe secondary glaucoma.

\section{Purpose of the study}

This work builds on earlier qualitative research by Green and colleagues into the impact of glaucoma diagnosis and sight loss. ${ }^{16}$ It is part of an ongoing, multimethod investigation into the experiences of African-Caribbean patients in the hospital and community eye services, which includes interviews with patients about their experiences from diagnosis to surgery and beyond. ${ }^{15,17,18}$ Sandwell and West Birmingham Local Research Ethics Committee gave approval for the study.

\section{Data collection}

The sampling was purposive, the inclusion criterion being all post-trabeculectomy, African-Caribbean patients $(\mathrm{N}=28$ at the time) attending one specialist glaucoma clinic at a regional ophthalmology center. There were no exclusion criteria beyond ability to communicate in English. Fifteen patients expressed interest on initial contact. Some (older) patients decided on reflection, that they would rather not go ahead, for some, other commitments supervened. Ultimately, eight patients gave their informed consent to be interviewed. Semi-structured qualitative interviews were used to collect the data and an interview guide was developed. Participants were asked to recount when they first became aware of a problem with their eyes and their feelings at the time. Subsequently they were probed about their subjective experiences of becoming a glaucoma patient, receiving treatment, the decision to undergo surgery, and its aftermath. MG and VC conducted the interviews, which were recorded with permission. The transcripts were transcribed and coded using both manual and computer-aided methods (NVivo $^{\odot}$; QSR International, Melbourne, Australia). Interpretation and inferences were validated through discussion of emerging concepts within the research team and checking back with participants where possible.

For the purposes of this paper, we present preliminary data comprising 'fully formed narratives' (see below) from three men of different generations. Collectively they characterize key concerns about African-Caribbean glaucoma namely, early onset, male prevalence, aggressive disease, and low levels of community awareness. Individually, each highlights a particular clinical and experiential perspective on being a glaucoma patient, which provides a focus for reflection on the nature of the surgeon-patient relationship. Their clinical and demographic profiles are detailed in Table 1.

\section{Data analysis}

When remembering and reflecting on experiences individuals often organize events into coherent stories, particularly where there has been dissonance between the ideal and real, self and others. ${ }^{19-21}$ Narratives are stories that recount a sequence of

Table I Characteristics of the participants

\begin{tabular}{|c|c|c|c|}
\hline & Nathan & Michael & Selwyn \\
\hline Age (yrs) & 19 & 43 & 74 \\
\hline \multirow[t]{5}{*}{ Social history } & Single parent & Married & Lives with wife \\
\hline & Living with & Two small & Retired \\
\hline & Mother & children & $\begin{array}{l}\text { Not eligible to } \\
\text { drive }\end{array}$ \\
\hline & Not employed & Manual worker & \\
\hline & Not eligible to drive & Not eligible to drive & \\
\hline Duration of glaucoma (yrs) & 8 & 6 & 6 \\
\hline Type of glaucoma & Secondary OAG & Juvenile OAG & Primary OAG \\
\hline Highest IOP $(\mathrm{mmHg} \mathrm{R}+\mathrm{L})$ & 54,44 & 42,44 & 28,37 \\
\hline Cup disc ration $(\mathrm{R}+\mathrm{L})$ & $0.9,0.9$ & $0.9,0.9$ & $0.8,0.8$ \\
\hline Visual field loss $(R+L)$ & Advanced $\mathrm{R}+\mathrm{L}$ & Advanced $\mathrm{R}+\mathrm{L}$ & Advanced $\mathrm{R}+\mathrm{L}$ \\
\hline Previous glaucoma surgery & $x 4$ & $x 3$ & $x \mid$ \\
\hline
\end{tabular}

Abbreviations: IOP, intraocular pressure; OAG, open-angle glaucoma. 
events that happened, which are significant for both narrator and audience. ${ }^{22}$ Although the temporal sequence may not be as ordered in the telling, they comprise a plot, beginning, middle and end, and an internal logic that makes sense to the narrator. Several writers describe procedures for reordering transcripted data into a temporal sequence by creating core stories and 'stories within stories' [sub-plots]. ${ }^{23-25}$ There is no single theoretical basis or standard approach associated with narrative analysis. However, sociolinguistic approaches are widely used because they focus not only on content, but also on the structure and social interaction within narratives. ${ }^{26,27}$ A structured narrative comprises an 'abstract' (what the story is about), 'orientation' (description of situation and context), 'complicating action' (main account of events), 'evaluation' (highlights point of the story), resolution (outcome), and coda (indicates closure). ${ }^{26}$ Although some may be absent, a fully formed narrative contains all six elements. The evaluative component is considered especially important because, "narrative is a presentation of the self, and the evaluative component in particular establishes the kind of self that is presented". ${ }^{28}$

In line with this the transcripts were reduced to three core stories using the procedure shown in Table 2. These core stories were organized around four stages signalled in the interview guide: being alerted to a serious problem; receiving the glaucoma diagnosis; facing up to treatment and surgery; life after surgery. Subsequently, a fully formed narrative or sub-plot within each core story was chosen because it contained powerful images of actions and emotions associated with the impact of the diagnosis and the surgeon-patient relationship. These core stories and sub-plots were used to make comparisons between events described by the participants and derive thematic analyses of their experiences.

\section{Interpretation of the findings}

Several sources of data are provided in the paper for readers to consider the interpretation (Figure 1). Excerpts from

Table 2 Stages in core story development

- Content of transcripts reviewed and organised chronologically.

- Prompt questions deleted.

- Cross referencing with original transcripts to confirm and validate meanings.

- Combination of remaining elements into a coherent story.

- Checking back with participants to verify story. these, and from the original transcripts, are used as illustrative examples of how actions and events were linked to themes derived from interpretation. The three core stories charting each man's glaucoma journey are included as Appendices 1-3 (pseudonyms are used in each case). The structured narratives or sub-plots are shown in Table 3. Excerpts used in the texts are annotated appropriately as follows: participant's initial, core story (CS), original transcript (OT), sub-plot (SP). Michael's sub-plot was the starting point for interpretation. It centered on the impact of receiving a diagnosis of glaucoma, and meeting with the glaucoma surgeon.

\section{Impact of the glaucoma diagnosis}

The abstract and orientation of Michael's story (Table 3) mark it as an 'atrocity story" ${ }^{29}$ - "I was devastated", "it hit me like a tornado". Reading this as simply a reporting of events, the psychological effect of distressing news delivered 'abruptly' and in an unsympathetic manner by professionals and the key message, "It was frightening" stands out. There is an implicit accusation that Michael has been dilatory and irresponsible, and must take the consequences.

...he was under the impression that I would have been aware about the eyes from the time, you know, that I first noticed it was going blurred. ... he stressed how worse the condition, the actual state, the damage level of the optic nerve in both eyes. (M:SP)

However, in portraying himself after this distressing event, Michael sets out to refute this and establish his identity as a responsible person in relation to health issues. His actions were understandable because another professional gave him wrong information. He reinforces this responsible identity in his account of the post-surgery period (Appendix 1).

I didn't think it was an issue at the time because at the time I was told my eyesight was perfect. If there was a more thorough check at the beginning I would have taken more early steps. (M:CS)

He also explains his actions in terms of lack of knowledge and awareness of glaucoma.

I did not know any family history of glaucoma. I did not even know what glaucoma was at the time. When my mother told me her brother went blind in his forties or fifties and he had no diabetes, I assumed the connection was from her side of the family. (M:OT)

Nathan's and Selwyn's stories (Table 3) support and augment the themes emerging from Michael's story. 


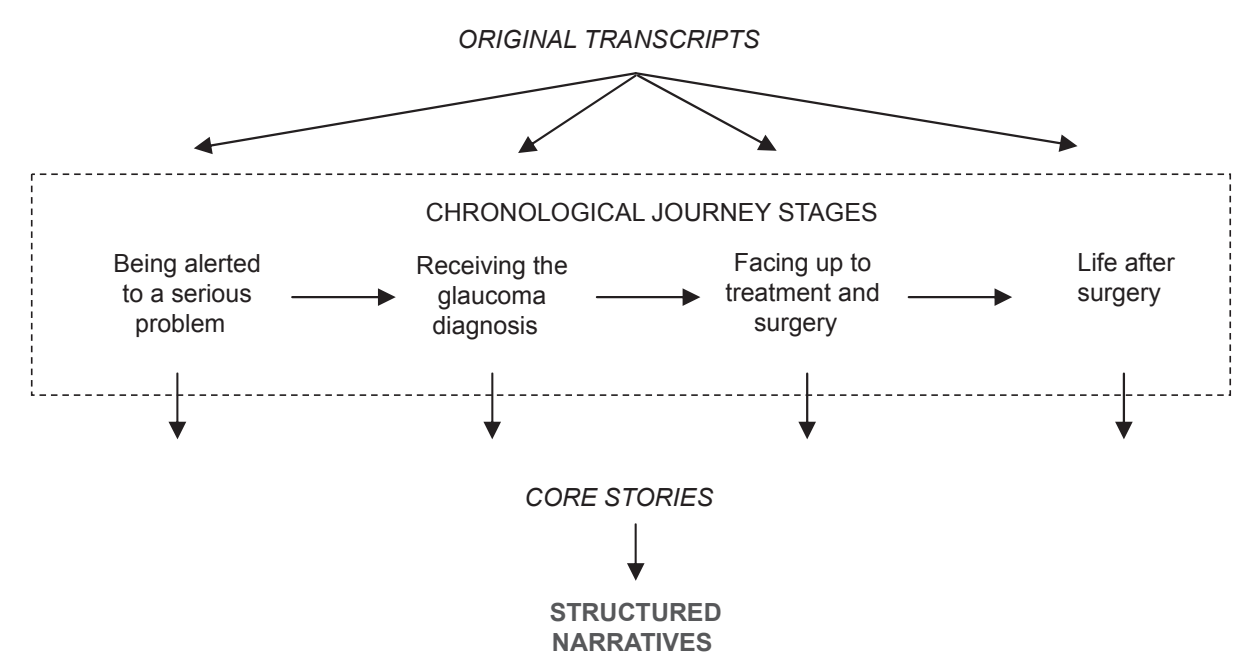

Figure I Analytical framework.

Nathan was also unaware of a family history (grandfather) until receiving his own diagnosis. He portrays himself as informed but anxious in the context of his identity as an experienced ophthalmic patient.

I didn't know if to expect something good coming out of it, or something bad coming out of it or what. I've had eye problems since the age of four or five, so establishing something new in an eye condition was just like, normal really. (N:CS)

Selwyn is the most sanguine for two reasons. First he is aware of a family history of blindness, secondly, "I didn't feel any way, because when you're getting old things does happen ..." (S:CS). Thus, the impact of a glaucoma diagnosis on these three men is constructed along a continuum from 'devastated' to 'sanguine',

Table 3 Sub-plots

\section{Michael}

Abstract: what the story is about

Orientation: establishes situation, context

Complication: main account of events and how these are made sense of by the narrator

Evaluation: highlights the point of the story

Resolution: outcome, what finally happened

Nathan

Abstract: what the story is about

Orientation: establishes situation, context

Complication: main account of events and how these are made sense of by the narrator
Obviously I was, you know, worried, very worried, and first, when he told me that I had the condition, I was devastated.

Originally, the one specialist, I was very tense with. When he told me the point I had glaucoma it hit me like a tornado and he stressed how bad the condition was.

He was quite abrupt, as he was under the impression that I would have been aware about the eyes from the time, you know, that I first noticed it was going blurred. But, as I say, I wasn't aware of glaucoma and my sight problems. Because the type of work that I do, I have regular eye checks. But, there's two types of eye checks, and after I do my research I find that they don't check pressures in your eyes. The type of eye test I was getting from work was by a nurse that was coming in just to check your eyesight. So when I had that I was given the all clear, I was fine. So when I went to the optician and given a more detailed eye test, and says there were high pressures in my eyes, that's when I start to worry.

Then, when he told, me, the first consultant, that I had glaucoma, you know, quite abrupt, he stressed how worse the condition, the actual state, the damage level of the optic nerve in both eyes. It was quite frightening to hear that.

But when they referred me to (the specialist) who specialises in glaucoma in Afro-Caribbean people I was very, very comfortable because he assured me that he would do everything he can.

\section{Well, it started I had an appointment.}

Then he said the pressure in my eye was fifty, which is extremely high. And he said, "Well, we're going to have to operate to get the pressure down, otherwise I will go blind, within a few months.

So he asked me would I prefer to have an operation, rather than the eye drops. 'Cos obviously the eye drops are going to take longer to take down the pressure. So it was a three-way decision really. It was me, my Mom and the doctors all agreeing at the same time. 
Table 3 (Continued)

Evaluation: highlights the point of the story

Resolution: outcome, what finally happened

Coda: indicating closure

\section{Selwyn}

Abstract: what the story is about

Orientation: establishes situation, context

Complication: main account of events and how these are made sense of by the narrator

Evaluation: highlights the point of the story

Resolution: outcome, what finally happened
Yeah, I was in total control really, 'cos if I didn't want to have the operation, then, I wouldn't have it.

It's kind of important because, obviously, I mean if I'm not in total control and the doctor's saying, obviously I need to operate, and obviously, l'm not saying you need to operate then there's no comparison, there's no bond where the doctor is getting on with the patient.

'Cos it's like a rocky road, actually. You never know what's going to be at the end, you never know what's going to happen half way in between. You've got to keep that bond between you and the specialist at all times.

Well I could see that me eyes wasn't working as good as it was before, but I put I down to age, so I says "Oh I got to get the glasses." So I been to the optician and him, he tells me that he thinks there is glaucoma in the eyes and, he refers me back to my doctor.

Then my doctor sends me to the hospital and straight away they tell me that I had glaucoma.

I didn't feel any way, because when you're getting old things does happen and I know that it was in my family. I am not really the worrying type. I don't care how bad it is and I can train myself for that, because when you worry it doesn't make it any better. I said to him (surgeon) "Is that what it is?" I says "Well, what will we do then?" He says, "Well you'll have an operation." I says, "Well, what suppose I don't want an operation?" He says, “Well, you'll get blinded." (Laughs)

I was worried about getting blind, that's the only thing I was really worried about. Because when he said, "There is a chance that you will be able to see properly if it works alright, but if you don't, you will blind anyway." So, it was a bit worrying but not too much.

So I says, “Alright then, I'll have an operation!” So we did the operation, and I didn't think anything could go any better. the mediating factors being related to expectations, message transmission, and glaucoma awareness (Figure 2).

\section{Meeting the glaucoma surgeon}

Resolution in the form of reassurance is achieved for Michael when he meets his glaucoma surgeon. In terms of fictional journey tales this is analogous to the appearance of a mentor. Mentors know the territory. Throughout the journey they support and challenge their charges to continue. They protect and encourage, clear obstacles, explain mysteries and point the way forward. "We greet them with awe and, above all, hope". ${ }^{30}$ This view pervades Michael's

\section{RESPONSE CONTINUUM}

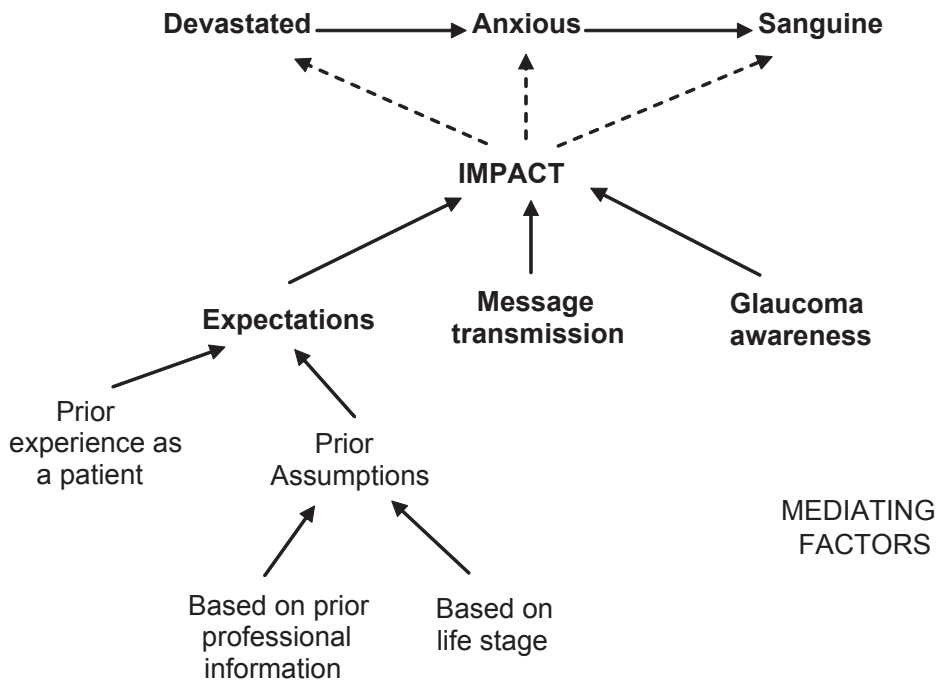

Figure 2 Thematic framework of responses to glaucoma diagnosis. 
descriptions of his meeting and subsequent interactions with his surgeon.

I was very, very comfortable because he assured me that he would do everything he can. (M:SP)

Such reassurance is important in the challenges and ordeals associated with an onerous treatment regimen, eventual trabeculectomy, and again in the post-surgery period.

He told me what could happen ... he explained the detail and told me the risk involved. (He) talk me through every examination ... I get a lot of positive with what he said and with that I feel really good. (M:CS)

Added confidence comes from the fact that his surgeon has recognized ethnic-specific expertise. Peer validation combined with empathy, respect and information giving are represented in the story as the reasons for Michael's bestowing trust on the surgeon.

...the best is that he's had more dealings with Afro-Caribbean and glaucoma cases. I felt as though I was in very good hands and the other consultants, they say the same thing. So I felt at ease, more comfortable. I left everything in his hands and I was very grateful. (M:CS)

Positivity both in content and delivery is also a key factor in Nathan's account of interactions with his surgeon. He gives a clear rationale for its importance to him.

I've come across some doctors where they've had a load of pauses in between what they were saying to me, which I wasn't really comfortable with. I probably think its 'cos they're unsure. I mean if someone's talking about something you really need in life, they have to be a hundred per cent confident in what they have to say. So stuttering and pausing is going to make you think, "Well if he's not sure how am I supposed to be?” (N:OT)

From one perspective Nathan's sub-plot (Table 3) reads as an example of participatory decision-making in action. In his evaluation of events (in response to a probe about how far he felt in control of decision-making) he casts himself as equal partner in the process. However, how he perceives his responsibilities as a patient is revealed in his account of the story's outcome (resolution) and coda. "It's kind of important ..." not to break the bond between surgeon and patient. He sees maintaining the bond is his responsibility.

'Cos it's like a rocky road, actually. You never know what's going to be at the end, you never know what's going to happen half way in between. You've got to keep that bond between you and the specialist at all times. (N:SP)
This conceptualisation of the mentor (surgeon) as both guide and gatekeeper, with the key to successful passage, able to select or reject the traveller ${ }^{24}$ appears again in his account of the post-surgery period.

The main thing that makes the glaucoma positive is having the people around you and the support. But also the specialist, because obviously if you never had the specialist, you never know what would happen. (N:CS)

As in other illness experiences, becoming a glaucoma patient may be seen as a stressful life transition. Perceptions of self-efficacy can be a valuable resource or a vulnerability factor in coping with such transitions. Although conceived as a trait, general self-efficacy is changeable, becoming more elaborated and stable as people age. ${ }^{31}$ Reading his core story in this context it is not surprising that, in comparison with the two younger men, high perceived self-efficacy stands out as the theme of Selwyn's journey. His accounts of conversations with the surgeon are suffused with humor. Their relationship is portrayed as reciprocal and less dependent. The surgeon earns respect by being "friendly and courteous."

He speak to you, ask you how you are getting on ... you feel like that's someone that is interested in you, because he's asking you everything that is important. (S:OT)

Likewise, Selwyn's anticipation of surgery is action-focused. He draws on a repertoire of external, personal and spiritual resources that help him face the ordeal with confidence.

I was looking forward for the operation, because I read a lot of health books, and I understand what life is. So I start detoxing my body, and I try to get my blood pure and circulation, to get ready for the operation, eating the right stuff .... But I was praying as well ... I believe God can do anything, as long as you ask Him sincerely. (S:CS)

In contrast, Michael and Nathan talk of anxiety or panic at the thought of someone cutting into "the most delicate part of the human body" (M:CS).

You're panicking and don't know what to do ... if you never had an operation before ... an eye operation is something you don't want to have first. (N:CS)

\section{Post-surgery reflections}

Michael looks back on his journey with regret at lost opportunity, but thankfulness that he can protect his children from the same ordeal. Nathan fears a bleak future, while for Selwyn, there is optimism and a return to former pleasures.

I wish I knew about this a lot sooner. If I was aware about it from day one, of my family history of it, then I would 
have thought about having regular eye tests, and probably wouldn't be as bad as it is now. (M:CS)

I don't really know what to expect. I mean I can't really say how long I've got before I do lose both eyes, or before I lose one. So I don't really look into the future. I try to take it one day at a time. (N:CS)

I can see better and better, now I can read that without glasses. So I have no complaint whatsoever, only praise. (S:CS)

\section{Summary of the findings}

A thematic summary of the narratives is shown in Figure 3. It comprises three overlapping elements. First is the outward journey, traveled in stages from life before glaucoma, across the threshold of diagnosis, through the labyrinth of treatment, towards the supreme ordeal of surgery. Typically, crossing the diagnostic threshold occurs in the specialist's consulting room, and this pivotal character in the story makes up the second element. For these men, respect for the authority of the specialist as information-giver, surgeon, and director of the glaucoma care process was fundamental to facilitating the outward journey and the achievement of clinical goals. The stories also take the three men on an inward journey in which they change and develop, moving from one way of being to the next: from despair to hope, weakness to strength, towards a changed identity. Surgeon-patient relationships are central their developing effective coping strategies. Support in facing the ordeals ahead, challenges to take on new responsibilities, and helping to envision a meaningful life with glaucoma, are fundamental to fostering trust and maintaining motivation to continue.

\section{Discussion}

Self-care and resourcefulness are important dimensions in patients' responses to chronic illness, and the doctor-patient relationship is central to developing effective coping strategies. Most complaints about doctors relate to poor communication, often within secondary care medicine where most medical education occurs. ${ }^{32}$ In describing their experiences all three patients draw attention to what they consider are the surgeon's duties and obligations. These encompass not only expertise as a surgeon and information source, but also willingness to confirm their identity as people and individuals. Theorized as a relational and dynamic process, identity is always in motion, dependent in part, on social and contextual interaction. ${ }^{33,34}$ Here, each patient establishes his own identity in terms of what he perceives as his duties and obligations towards the relationship with the surgeon. For example, Nathan casts himself as keeper of the bond between himself and the surgeon along the 'rocky road' towards an uncertain future. Michael identifies himself as compliant and responsible, in opposition to the 'designated

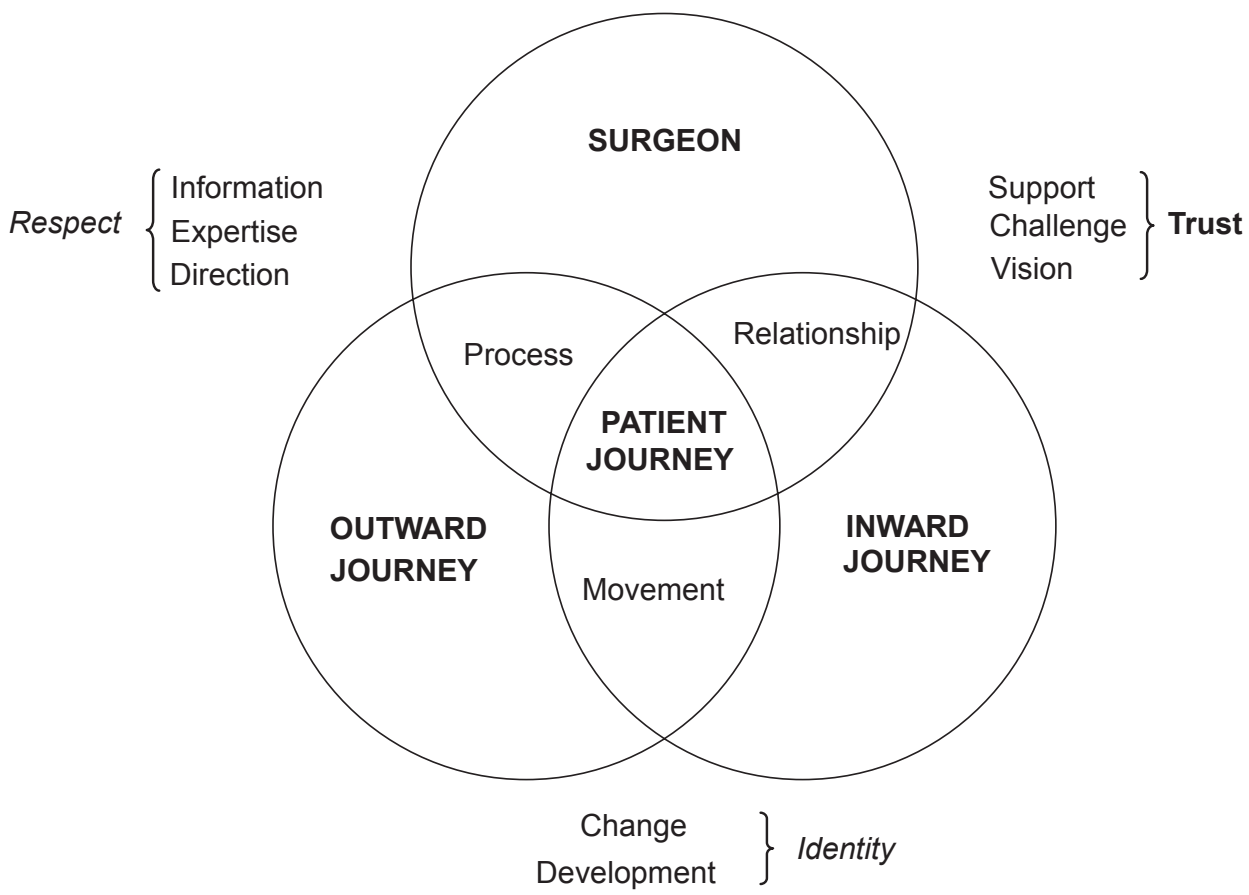

Figure 3 Thematic framework for the patient's surgical glaucoma journey. 
identity' bestowed by his first consultant. He is "grateful", and places himself in the surgeon's hands. Selwyn presents himself as an active agent in his own destiny, "So, we did the operation and it could not have gone better."

These perspectives resonate with critiques of patient partnership, which question its meaning and warn against its acceptance as a new form of orthodoxy in health care. ${ }^{35,36}$ Partnership has been likened to patients 'coming of age'; "Patients have grown up, and there's no turning back". 37. However, critics point out that partnership reflects the way people are positioned in relation to one another, and the way the space between them is negotiated. Positioning is a fluid construct that varies from moment to moment within social interactions. Individuals shift from one perception of themselves to another, as their positions within various narratives are taken up or assigned. Unlike roles, which are fixed and formally defined, positions are contestable and tacit. ${ }^{38}$ In this regard the metaphor of surgeon as mentor is a useful one. A key function of mentors is to assist their protégés to reevaluate their perceptions and beliefs about issues and events. They are transitional figures, helping protégés 'grow up' and develop their identities. ${ }^{30}$ In so doing, mentors move between positions as the story unfolds.

Like guides, we walk at times ahead of our (patients), at times beside them, and at times we follow their lead. In sensing where to walk lies our art. For as we support (them) in their struggle, challenge them towards their best, and cast light on the path ahead, we do so in respect for their potential and our care for their growth. ${ }^{30}$

In the context of chronic disease, this conceptualization enables negotiation and renegotiation of the social space between doctor and patient in tune with clinical, emotional and developmental needs at any given moment. There is legitimate room for paternalism (walking ahead), participation (walking beside) and partnership (patient leading on the basis of experiential expertise). The challenge for glaucoma surgeons concerned to improve the surgical journey for patients, is to see and facilitate each individual's movement and know where best to walk.

Good clinical care demands practitioners reflect constantly on their practice, listening to what patients need, as well as what is considered convenient or appropriate to provide. When policy dictates that money follows patients, this principle becomes even more salient. ${ }^{39,40}$ But determining patients' needs, and sensitivities within limited consultation times is a daunting task for even the most experienced practitioner, and it is likely that more and better training in communication skills and patient-centered care will be required..$^{37,41}$ Nevertheless, the value of narratives lies in their ability to enforce reflection. ${ }^{42}$ Therefore, gaining access to patients' narrative accounts of their subjective experience is a worthwhile endeavor for glaucoma services.

The three stories presented here are not interpreted simply as 'true' reports on reality. Rather, they are viewed as separately constructed narratives that, as a collection, give deeper insight into the subjective viewpoints of glaucoma patients than could be reached in a single account. By reading each story in light of the others, they form the beginning of a community narrative that gives meaning, understanding and expression to the experience of AfricanCaribbean patients in the glaucoma care system. To make the experiences of the men portrayed here accessible to the wider community, their powerful accounts have been crafted as an intergenerational, interactive theatre piece by local African-Caribbean playwright and co-author (MG). Designed for a wide range of performance spaces, it aims to stimulate community engagement in addressing glaucoma awareness and under-utilisation of eye-care services among young African-Caribbeans. As importantly, it involves the community in defining best practice in relation to culturally sensitive glaucoma service delivery.

\section{Conclusion}

This paper has used the subjective experiences of three African-Caribbean glaucoma patients to demonstrate the usefulness of narrative research as a basis for reflective practice and a framework for approaching patients' problems holistically. The patients' stories were presented as an important resource for enhancing communication skills and patient-centered glaucoma care, as well as a tool in preventing avoidable glaucoma blindness.

\section{Acknowledgments}

We thank all the patients for sharing their glaucoma stories and giving up their time to participate in the study.

\section{Disclosure}

VC and MG designed the study, and interviewed the participants. VC and MG were involved in data analysis and preparation of the paper. SC contributed to the data collection and analysis process. PS conceived and is leader of the Birmingham ReGAE Project and reviewed the final draft. PS is the guarantor. The following organizations funded the research: Birmingham Strategic Health Authority; Heart of Birmingham Teaching Primary Care Trust; City Hospital NHS Trust; Pfizer UK; Birmingham Social Services. 


\section{References}

1. Humphrey C. Ways of seeing: Biomedical perspectives on the social world. J R Soc Med. 2006;99:602-6.

2. Madjar I, Kacen L, Ariad S. Telling their stories, telling our stories: Physicians experiences with patients who decide to forgo or stop treatment for cancer. Qual Health Res. 2007;17:428-41.

3. Lapsley P, Groves T. The patient's journey: traveling through life with a chronic illness. BMJ. 2004;329:582-3.

4. Evans RG. Patient centred medicine: reason, emotion, and human spirit? Some philosophical reflections on being with patients. MH Online. 2003 [cited 2006 Jan 1]; 29:8-14. Available from: http://mh.bmj. com/cgi/content/abstract/29/1/8.

5. Greenhalgh T, Hurwitz B. Narrative based medicine. Why study narrative? BMJ. 1999;318:48-50.

6. Clever LH. Some things have not changed. Ann Intern Med. 2000;132:85-9.

7. Cooper LA, Beach MC, Johnson RL, Inui TS. Delving below the surface: understanding how race and ethnicity influence relationship in health care. J Gen Intern Med. 2006;21:S21-27.

8. Cooper LA, Powe NR. Disparities in patient experiences, health care processes, and outcomes: the role of patient-provider racial, ethnic, and language concordance. Report No. 753. The Commonwealth Fund; 2004.

9. Krishnan JA, Diette GB, Rand CS. Disparities in outcomes from chronic disease. Impaired patient-physician partnerships may be an important cause in minorities. BMJ. 2001;323:950.

10. Leske MC, Connell AMS, Wu S-Y, Hyman LG, Schachat AP. The Barbados Eye Study Group: Risk factors for open-angle glaucoma. Arch Ophthalmol. 1995;113:918-24.

11. Dietlin TS, Jordan J, Dinslage S. What do glaucoma specialists know about the patients? Graefes Arch Clin Exper Ophthalmol. 2005;244:859-62.

12. Racette L, Wilson MR, Zangwill LM, et al. Primary openangle glaucoma in Blacks: a review. Surv Ophthalmol. 2003; 48:295-313.

13. Fraser S, Bunce C, Wormald R. Retrospective analysis of risk factors for late presentation of chronic glaucoma. Br J Ophthalmol. 1999;83:24-8.

14. Wormald R, Basuri E, Wright L, Evans J. The African Caribbean Eye Survey: Risk factors for glaucoma in a sample of African Caribbean people living in London. Eye. 1994;8:315-20.

15. Cross V, Shah P. ReGAE 2: glaucoma awareness and the primary eye-care service: some perceptions among African-Caribbeans in Birmingham UK. Eye. 2007;21:912-20.

16. Green J, Siddall H, Murdoch I. Learning to live with glaucoma: a qualitative study of diagnosis and the impact of sight loss. Soc Sci Med. 2002;55:257-67.

17. Cross V, Shah P, Glynn M, Chidrawar S. ReGAE 4: Trabeculectomy for advanced glaucoma: The surgical journey of African-Caribbean patients. Eye. Epub 2008 Jan 18.

18. Shah P, Cross V. ReGAE 1: The Shah-Cross Model as an orientating framework in African-Caribbean glaucoma awareness research, Eye. 2006;20:988-97.

19. McCance TV, McKenna HP, Boore JRP. Exploring caring using narrative methodology: and analysis of the approach. J Adv Nurs. 2001;33:350-6.
20. Chamberlain K, Stephens C, Lyons AC. Encompassing experience: meanings and methods in health psychology. Psychol Health. 1997;12:691-709.

21. Reissman CK. Narrative analysis. Newbury Park, CA: Sage Publications; 1993.

22. Denzin NK. Interpretive Interactionism. London: Sage Publications; 1989.

23. McLeod J, Balamoutsou S. A method for qualitative narrative analysis of psychotherapy transcripts. In: Frommer J, Rennie D, editors. Qualitative psychotherapy research: Methods and methodology. Lengerich, Germany: Pabst Science Publishers; 2001.

24. Kelly T, Howie L. Working with stories in nursing research: procedures used in narrative analysis. Int J Mental Health Nurs. 2007;16:136-44.

25. Emden C. Conducting a narrative analysis. Collegian. 1998;5:30-35.

26. Labov W. Speech actions and reactions in personal narratives. In: Tannen D, (editor) Analysing Discourse: Text and Talk, Washington DC: Georgetown University Press; 1982.

27. Labov W, Waletsky J. Narrative analysis. In: Helm J, editor. Essays in on the Verbal and Visual Arts. Seattle, WA: University of Washington Press; 1967.

28. Linde C. Life stories: The creation of coherence. New York, NY: Oxford University Press; 1993.

29. Silverman D. Interpreting qualitative data. London, UK: Sage Publications; 2001.

30. Daloz L. Mentor: Guiding the journey of adult learners. San Francisco: Jossey-Bass; 1999.

31. Jerusalem M, Mittag W. Self-efficacy in stressful life transitions. In: Bandura A, (editors) Self-efficacy in changing societies. Cambridge, UK: Cambridge University Press; 1995.

32. Birks YF, Watt IS. Emotional intelligence and patient-centred care. J R Soc Med. 2007;100:368-74.

33. Sfard A, Prusak A, Cheek J. Telling identities: In search of an analytical tool for investigating learning as a culturally shaped activity. Educ Res. 2005;34:14-22.

34. Juzwik MM. 2006 Situating narrative-minded research: a commentary on Anna Sfards and Anna Prusak's “Telling identities". Educ Res. $35: 13-21$.

35. Cheek J. Negotiated social space: a look at partnership in contemporary health care. Primary Health Care Research and Development. 2003; 4:119-27.

36. Taylor D, Bury M. Chronic illness, expert patients and care transition. Sociol Health Illn. 2007;29:27-45.

37. Coulter A. Paternalism or partnership? Patients have grown up-and there's no going back. BMJ. 1999;319:719-20.

38. Cook AJ, Moore K, Steel GD. The taking of a position: A reinterpretation of the elaboration of likelihood model. J Theory Soc Behav. 2004; $34: 315-31$.

39. Stone R. 2006. The Struggle for cultural competence. The Guardian. 2006 April 12.

40. Department of Health. Money follows the patient. [Cited 2007 Sept 15] Available from: http://www.dh.gov.uk/en/Policyandguidance/ Organisationpolicy/Healthreform/DH_4135987.

41. Cohn F. Existential medicine: Martin Buber and physician-patient relationships. J Contin Educ Health Prof. 2001;21:170-81.

42. Swift TL, Dieppe PA. Using expert patients' narratives as an educational resource. Patient Educ Couns. 2005;57:115-21. 


\section{Appendix I Michael's story Being alerted to a serious problem}

First time I can recollect I had problems in my eyes is round about 2002. What happened right, my right eye just got, well just got progressive blurriness as opposed to my left eye. I was just putting it down to, you know, stress at work and bringing up a family, as at that time, we had twins, and I was working long hours and the type of work I do.

To be honest with you, up until 3 years ago I didn't even know about the condition glaucoma. It wasn't until 2003 that I actually I went to the optician and they tell me that I have a high level of pressure in both eyes, so what they do is refer me to the eye hospital. Obviously this is where they did a more fuller test.

\section{Receiving the glaucoma diagnosis}

Obviously I was, you know, worried, very worried, and first, when he told me that I had the condition, I was devastated. Originally, the one specialist, I was very tense with. When he told me the point I had glaucoma it hit me like a tornado and he stressed how bad the condition was. He was quite abrupt, as he was under the impression that I would have been aware about the eyes from the time, you know, that I first noticed it was going blurred. But, as I say, I wasn't aware of glaucoma and my sight problems. Because the type of work that I do, I have regular eye checks. The type of eye test I was getting from work was by a nurse that was coming in just to check your eyesight. So when I had that I was given the all clear, I was fine.

Then, when he told, me, the first consultant, that I had glaucoma, you know, quite abrupt, he stressed how worse the condition, the actual state, the damage level of the optic nerve in both eyes. It was quite frightening to hear that.

But when they referred me to (the specialist) who specializes in glaucoma in Afro-Caribbean people I was very, very comfortable because he assured me that he would do everything he can.

\section{Facing up to treatment and surgery}

I'd say I was very depressed. Obviously I took on board what the specialist says my options were. I had immediate treatments, three sets of eye drops, and sticking to the routine of putting in the right eye drop at the right time, and going back, monitoring the pressure levels and all that, making sure it's the target. They said that although the pressure was going down with those drops, they said that the operation, surgery, would be the best way of getting the pressures down even further, and give me the best possible chance of you know, restoring what's left of my sight.

The specialist said the operation was the last resort. He went into great details and explained to me, he was more concerned because of my age. He told me what could happen if I didn't have the operation, I could be blind within 5 years. He explained the detail to the operation, and told me the risk involved. He also says there was a high percentage of success in the operation. It wasn't available 5 years before, and he's had some success with. Well, the thought that was going through my mind was the operation, and whether it was going to be a success and the possibility of going blind. But when it come to a point where he says well an operation is necessary, I took the decision to go along and have the operation done.

I was very nervous because, you know, the operation was, you know, in my opinion, on the most delicate part of the human body. He reassured me that there is a very high percentage of success, but also he did state there was, you know, there could be problems, could even go blind during the operation so either way, there were more pluses having the operation than not having it done. So I was a little nervous but, as I say, he reassured me every step of the way. I don't think I would have got that kind of treatment with another consultant and the best is that he's had more dealings with Afro-Caribbean and glaucoma cases. I felt as though I was in very good hands and the other consultants they say the same thing. So I felt at ease, more comfortable. I left everything in his hands and I was very grateful.

\section{Life after surgery}

The first moment I woke up relieved as I was still here, and when they come to examine me, they firstly say the operation went better than expected. It was just a huge weight off my shoulder.

Even in the aftercare, I had regular visits to the hospital. Keep taking the eye drops until they say and don't do any physical stuff. Don't lift anything heavy, because obviously it will put undue pressure and undo the work that they've done. So I had very good after care, as I say. Had a brilliant consultant, you know, talk me through every examination. I get a lot of positive with what he said, the operation and how its gone, the targets that they've set with the pressures in the eyes, and absolutely overjoyed and with that I feel really good, I felt really happy.

It's more of a mental thing rather than a physical thing in my case. It's mentally in the back of your mind this disease. I mean, I still get a little depressed about it because, well, it's 
a good thing really. With me having kids they are obviously going to be at risk of having this when they get older, but because I'm aware of it, if there is any development of glaucoma in my children they will detect it earlier rather than later in my case. If I was aware about it from day one, of my family history of it, then I would have thought about having regular eye tests, and probably wouldn't be as bad as it is now.

All I value is that, I'd say the eye is the most precious thing in the human body. You can't take it for granted. I'd never think that before at all. Did not think that before because the work that I did, they type of work that I do and obviously, with the duty nurse coming in and regularly doing the eye check and you know, I didn't think it was an issue at the time because at the time I was told my eyesight was perfect. If there was a more thorough check at the beginning I would have taken more early steps. Get your eyes regularly tested, don't take it for granted that, you know, that your eyes are perfect. I mean, that's all that I can say.

\section{Appendix 2 Nathan's story Being alerted to serious change}

Well, it first started ... I had uveitis first. I found that my vision was deteriorating and I knew it wasn't due to the uveitis because I know it doesn't only do that to your eyes. So 'cos I normally have regular check ups any way, I told the doctor what's going on.

\section{Receiving the glaucoma diagnosis}

He said, you've been diagnosed with the glaucoma, which was about two years ago. I felt bad. I didn't know what to expect. I didn't know if to expect something good coming out of it, or something bad coming out of it or what. I've had eye problems since the age of four or five, so establishing something new in an eye condition was just like, normal really. But I didn't think it would get so bad.

Then he said the pressure in my eye was fifty, which is extremely high. And he said, "Well, we're going to have to operate to get the pressure down, otherwise I will go blind, within a few months. So he asked me would I prefer to have an operation, rather than the eye drops. 'Cos obviously the eye drops are going to take longer to take down the pressure. So it was a three-way decision really. It was me, my Mom and the doctors all agreeing at the same time.

Yeah, I was in total control really, 'cos if I didn't want to have the operation, then, I wouldn't have it. It's kind of important because, obviously, I mean if I'm not in total control and the doctor's saying, obviously I need to operate, and obviously, I'm not saying you need to operate then there's no comparison, there's no bond where the doctor is getting on with the patient.

'Cos it's like a rocky road, actually. You never know what's going to be at the end, you never know what's going to happen half way in between. You've got to keep that bond between you and the specialist at all times.

\section{Facing up to treatment and surgery}

"What's going to happen?" That was the only thing running through my head. I couldn't think straight or anything. 'Cos, I mean, I've had operations before, but on your eye it's just totally different because you never know what the outcome's going to be.

I felt weird, thinking that actually someone is going to cut your eye and you don't know if you're going to see out of that eye again. I mean, I had my Mom there for total support, which was OK. 'Cos some people don't have the support. Some people have to do it alone. But it is better if you've got someone beside you to talk to you and keep you calm basically.

Well, you get like a group of doctors coming to talk to you, and making sure you fully understand what is going to happen in the operation. Then they mark your skin, which eye they're going to operate on. Then they give you antibiotics, painkillers before the operation. Then you find that you've got to go 'nil by mouth' for twelve hours before the operation. So you're completely empty. Then you find yourself, that you're panicking and you don't know what to do. Because, obviously, if you've never come across it and you've never had an operation before, going to have an eye operation is something that you don't want to have first.

\section{Life after surgery}

I mean, there is times when I'm thinking, "I don't really want to go to the appointment because they're going to say the same thing, and give me the same thing in my eye, say the same thing over and over again. But I mean, at the end of the day I've got to go to all of my appointments, 'cos I never know myself what's going on in the eye.

It's affected me in a big way because obviously, due to ... it can hold you back from a lot of things. It can hold you back from college from seeing what's on the whiteboard or the blackboard. That's different, that's another setback. Going on the computer, that's another set back; finding that you have to go closer to the screen, which is damaging your eye even more. Obviously, if you can't really see properly you can't drive. Obviously, you're going to put other people in danger as well as yourself. 
I've tried to keep most of my relationships with family and friends the same, because I don't really want people to see me as a different person, because obviously, I'm not a different person, I'm the same person but with glaucoma. So at the end of the day I don't really want anyone to see me as a different person.

The main thing that makes the glaucoma positive is having the people around you and the support. But also the specialist, because obviously if you never had the specialist, you never know what would happen.

I mean I don't really, I haven't really looked into the future. I mean coming into my second operation on my eye, I mean, it's like set me back. I don't really know what to expect. I mean I can't really say how long I've got before I do lose both eyes, or before I lose one. So I don't really look into the future. I try to take it one day at a time.

\section{Appendix 3 Selwyn's story Being alerted to serious change}

Well I could see that me eyes wasn't working as good as it was before, but I put I down to age, so I says "Oh I got to get the glasses." So I been to the optician and him, he tells me that he thinks there is glaucoma in the eyes and, he refers me back to my doctor.

\section{Receiving the glaucoma diagnosis}

Then my doctor sends me to the hospital and straight away they tell me that I had glaucoma. I didn't feel any way, because when you're getting old things does happen and I know that it was in my family. I am not really the worrying type. I don't care how bad it is and I can train myself for that, because when you worry it doesn't make it any better. I said to him (surgeon) "Is that what it is?" I says "Well, what will we do then?" He says, "Well you'll have an operation." I says, "Well, what suppose I don't want an operation?" He says, "Well, you'll get blinded." (Laughs)
I was worried about getting blind, that's the only thing I was really worried about. Because when he said, "There is a chance that you will be able to see properly if it works alright, but if you don't, you will blind anyway." So, it was a bit worrying but not too much.

So I says, "Alright then, I'll have an operation!" So we did the operation, and I didn't think anything could go any better.

\section{Facing up to treatment and surgery}

I was looking forward for the operation, because I read a lot of health books, and I understand what life is. So I start detoxing my body, and I try to get my blood pure and circulation, to get ready for the operation, eating the right stuff. That's what I did.

I really grew up in a Christian home you see, and I definitely believe in prayer. You know, what I ask for, I will get, and I was hoping, all along I was hoping that this operation goes OK. But I was praying as well. Until I had the anaesthetic, I was praying, because that's what I believe in. I believe God can do anything, as long as you ask Him sincerely.

\section{Life after surgery}

When I got up, I felt quite strong really, I felt quite strong. I say, it can't have gone better. I knew it was alright because I wasn't feeling any pain. I wasn't feeling any pain at all. It's got to be alright if you're not feeling any pain. It take a little time for your eye to come around, but after that, it was perfect. It didn't stop me from doing anything at all, nothing at all, everything I used to do.

I do take eye food (laughs) what I call it 'super-treatment', I take it everyday and it seem to help as well. I that's what make my eyes better, but it does work.

I should say, whether you have glaucoma or not in your family, as long as your eye start deteriorating, have the check and if you find out that you have glaucoma, have an operation. 